\title{
A New Perspective About Diagnosing Rathke's Cleft Cyst: Localization of the Cyst in Reference to the Pituitary Gland Xiao Fan, ${ }^{1} \mathrm{Qi} \mathrm{Li}^{2},{ }^{2}$ Tianyou Luo, ${ }^{2,}$ Yun Mao, ${ }^{2}$ Ling $\mathrm{He},{ }^{1}$ Jinhua Cai, ${ }^{1}$ and $\mathrm{Ye} \mathrm{Xu}^{1}$ \\ ${ }^{1}$ Department of Radiology, The Children's Hospital of Chongqing Medical University, Chongqing, China \\ ${ }^{2}$ Department of Radiology, The First Affiliated Hospital of Chongqing Medical University, Chongqing, China \\ "Corresponding author: Tianyou Luo, Department of Radiology, the First Affiliated Hospital of Chongqing Medical University, No. 1 Youyi Road, Yuzhong District, Chongqing 400016, China. Tel: +86-2389012302/13983659609, Fax: +86-2368811487, E-mail: Itycqfs@126.com
}

Received 2017 February 19; Revised 2017 November 20; Accepted 2017 December 13.

\begin{abstract}
Background: Rathke's cleft cysts (RCCs) were diagnosed mostly by shape, signal intensity and enhancement characteristics on MR images.

Objectives: To identify the diagnosis of RCC by an improved understanding about the cyst's localization in reference to the pituitary gland.

Patients and Methods: We retrospectively evaluated 124 patients with pituitary cystic lesions, verified surgically and histologically. The patients were divided into RCC and cystic pituitary adenoma (CPA) groups. The cysts in both groups were observed and compared, focusing on the shape and size, as well as clinical and MRI features, especially localization. Receiver-operating-characteristic (ROC) curve was performed with the clinical and MRI findings between the groups.

Results: The RCC group included 90 patients (33 men) with a mean age of 40.9 years, while the CPA group included 34 patients (12 men) with a mean age of 43.5 years. On MRI, the RCCs were mostly located without shift of the pituitary stalk on the coronal view, with the superior margin of the cyst lying behind or across the junction point of the pituitary stalk on the sagittal view. The ROC curve was performed, and the following two variables exhibited good performances in diagnosing RCCs: the coronal localization (sensitivity, 91.1\%; specificity, 79.4\%; AUC = 0.853, 95\% confidence interval: $0.778-0.910, \mathrm{P}<0.0001$ ), and the sagittal localization (sensitivity, 88.9\%; specificity, 91.2\%; AUC = 0.889, 95\% confidence interval: 0.821 - 0.939, $\mathrm{P}<0.0001$ ).

Conclusion: Cyst localization, observed easily on MRI, can be used as an effective parameter for diagnosing RCC and distinguishing it from a CPA.
\end{abstract}

Keywords: Rathke’s Cleft Cyst, Embryology, Rathke’s Pouch, Localization, Magnetic Resonance Imaging

\section{Background}

Rathke's cleft cyst (RCC) is a benign, non-neoplastic lesion originating from the remnant of Rathke's pouch (1). Such lesions are often small and clinically silent throughout life, with an incidence of up to $22 \%$ on routine autopsies $(1,2)$. RCCs typically are diagnosed based on the shape, signal intensity, and enhancement characteristics of the lesions on MRI (3-6). However, to the author's knowledge, these MRI findings are not specific and may be difficult to interpret, such as differentiating the enhancement of the cyst wall from that of the normal pituitary gland, necessitating a cyst wall biopsy to obtain a more definitive diagnosis.

\section{Objectives}

Since an RCC develops between the anterior and posterior lobes of the pituitary gland (1), we wonder if this char- acteristic of RCC can be used for RCC diagnosis. The aim of this study was to identify and predict the diagnosis of RCCs by an improved understanding of the cyst's localization.

\section{Patients and Methods}

\subsection{Study Population}

Records of patients diagnosed with RCCs $(\mathrm{n}=90)$ and cystic pituitary adenomas (CPAs) $(n=34)$ between March 2012 and February 2015 from the department of radiology in the first affiliated hospital of Chongqing Medical University were retrospectively evaluated. The diagnosis was verified both surgically and histologically. The histological criteria for RCC is dense eosinophilic amorphous mucin containing small strips of simple cuboidal or pseudostratified columnar, ciliated epithelial cyst wall lining. These patients were divided into RCC and CPA groups. This study 
was approved by the review board and ethics committee of our institution.

\subsection{MRI Data Acquisition}

All MRI studies were performed with an 8-channel head coil on a 1.5-tesla system (Signa Horizon Lx; General Electric Medical System, Milwaukee, WI, USA). All patients underwent presurgical imaging within 1 week of the operation. Conventional MRI included coronal T1-weighted spin-echo (SE, repetition time (TR)/echo time $(\mathrm{TE})=360 / 14 \mathrm{msec}$ ), T2weighted spin-echo (SE, TR/TE $=2000 / 140 \mathrm{msec})$ and sagittal T1-weighted spin-echo (SE, TR/TE $=360 / 14 \mathrm{msec}$ ). The imaging parameters were: a $200 \mathrm{~mm} \times 200 \mathrm{~mm}$ field of view, a slice thickness of $3 \mathrm{~mm}$ with a $0.5 \mathrm{~mm}$ gap, and a matrix size of $320 \times 192$. Contrast-enhanced T1-weighted images were obtained in each patient after intravenous injection of $0.1 \mathrm{mmol} / \mathrm{kg}$ gadolinium-DTPA (Magnevist, Schering AG, Berlin, Germany), with a velocity of $1.5 \mathrm{~mL} / \mathrm{s}$.

Two experienced radiologists (Q.L. and X.F., both with 8 years of experience) reviewed the images. All lesions were reviewed for shape, size, localization, and signal characteristics, including signal intensity on T1 and T2 weighted images (T1WI, T2WI), presence of an intracystic nodule, or fluid-fluid level.

\subsection{Statistical Analysis}

The $\chi^{2}$ test was used for numerical data, such as sex, proportion of patients with each symptom, and MRI features between RCC and CPA groups.

Interobserver agreement between the two readers was evaluated with Kappa scores $(\kappa)$. Agreement was considered fair to good if $\kappa$-values were between 0.40 and 0.75 and high if values were $>0.75$.

Areas under receiver-operating-characteristic (ROC) curves (AUCs of ROC curves) were used to judge the diagnostic performance for each parameter with a significant difference between the groups, and logistic regression analysis was performed, producing values from 0.5 (no correlation) to 1.0 (perfect concordance) $(7,8)$.

AUCs were performed using MedCalc 12.7, while the rest statistical analyses were using SPSS for Windows (version21.0; SPSS, Chicago, IL, USA). A P value of $<0.05$ was considered statistically significant.

\section{Results}

\subsection{Baseline Characteristics of the Patients}

The data for age, sex, and symptoms between RCC and CPA groups are summarized in Table 1 . The study included 90 patients with RCCs, 33 men and 57 women, ranging in age between 6 and 76 years (average, $40.92 \pm 1.79$ years) at presentation. The clinical symptoms included headache (28 patients), visual impairment (14 patients), pituitary dysfunction (26 patients) and no symptoms (22 patients, who were misdiagnosed as having other cystic lesions by MRI). The comparison patients included 12 men and 22 women, ranging in age from 18 to 70 years (average, 43.53 \pm 2.72 years) at presentation. Their clinical symptoms included headache (nine patients), visual impairment (seven patients), pituitary dysfunction (17 patients), and no symptoms (one patient whose lesion was found incidentally on a screening MRI of the brain). There were no differences regarding sex and age between the groups $(\mathrm{P}=0.887$ and $\mathrm{P}=0.487$, respectively). Symptoms differed significantly, so further comparisons were made, and a significant difference was found between those with no symptoms and those presenting with space-occupying lesion causing symptoms $(\mathrm{P}=0.032)$ and pituitary dysfunction $(\mathrm{P}=0.002)$. Space-occupying lesion causing symptoms (42/90) was the most common presentation in the RCC group, while pituitary dysfunction (17/34) was most common in the CPA group.

Table 1. Differences in Baseline Characteristics Between Rathke's Cleft Cyst (RCC) and Cystic Pituitary Adenoma (CPA) Groups

\begin{tabular}{lccc}
\hline Baseline Characteristics & RCC & CPA & P Value \\
\hline Sex & F/M $(57 / 33)$ & F/M (22/12) & 0.887 \\
Age, $y($ mean \pm SD $)$ & $40.92 \pm 1.79$ & $43.53 \pm 2.72$ & 0.487 \\
$\begin{array}{l}\text { Symptoms } \\
\text { None }\end{array}$ & 22 & 1 & 0.009 \\
\hline $\begin{array}{l}\text { Space-occupying } \\
\text { symptom }\end{array}$ & 42 & 16 & \\
\hline Pituitary dysfunction & 26 & 17 & \\
\hline
\end{tabular}

${ }^{\mathrm{a}} \mathrm{P}$ value of comparison between two symptoms.

4.2. Size and Localization of Lesions in Reference to the Sella Turcica

Most of the 90 RCCs had an intrasellar location, at least partially, with 43 lesions contained completely in the sella and having a height of less than $1.2 \mathrm{~cm}$. An additional $43 \mathrm{le}-$ sions were larger, with a height of more than $1.2 \mathrm{~cm}$ (maximum: approximately $2.8 \mathrm{~cm}$ ), extending from within the sella to the suprasellar region. There were only four lesions that were completely suprasellar in location. A round or ovoid shape was observed for 83 lesions, while the remaining seven had snowman appearances.

Of the CPA patients, 14 lesions were located completely within the sella, while 20 lesions extended from within the intrasellar region to the suprasellar region. Lesion heights ranged from 0.5 to $2.3 \mathrm{~cm}$ on preoperative imaging. 
4.3. Localization of the RCC in Reference to the Pituitary Gland on the Coronal View

The cysts were located in the middle of the pituitary gland or laterally. Either lesion location could be found with or without shift of the pituitary stalk. There were two main types of localization of the RCC in reference to the pituitary stalk on the coronal view. The overwhelming majority (83 lesions, 92.2\%) of RCCs were located without shift of the pituitary stalk, while only seven (7.8\%) lesions were located with the pituitary shifted. On the other hand, CPAs were mostly located with the pituitary shifted (27 lesions, $79.4 \%$ ), with only seven (20.6\%) lesions located without shift of the pituitary stalk.

\subsection{Localization of the RCC in Reference to the Pituitary Gland on the Sagittal View}

In our study, all the RCCs and corresponding pituitary stalks were easily viewed at the same level on the sagittal view. We identified three localization types for the RCC in reference to the junction of the pituitary stalk with the pituitary gland. Least frequently, the inferior margin of the RCC in 10 patients was located in front of the junction (type 1, Figure $1 A$ and $2 A$ ). In 50 others, the superior margin of the RCC was located behind the junction (type 2, Figure $1 \mathrm{~B}$ and $2 \mathrm{~B}$ ), while the superior margin of the RCC in 30 patients was located across the junction (type 3, Figure $1 \mathrm{C}$ and $2 \mathrm{C}$ ) or encircled the pituitary stalk with a snowman appearance (type 3, Figure 1D and 2D). The last two types were more commonly seen (88.9\% in total).

In contrast, there were only three CPAs of type 2 or 3 in total (Figure 2F). The bulk of 16 CPAs did not overlap with their corresponding pituitary stalks on the sagittal view (Figures $1 \mathrm{E}$ and $2 \mathrm{G}$ and $2 \mathrm{H}$ ), the rest of 15 lesions were of type 1 (Figure $2 \mathrm{E}$ ). These two types comprised the majority of CPAs ( $91.2 \%$ in total).

\subsection{Comparison of Conventional MRI Characteristics and Le- sion Localization Between the RCC and CPA Groups}

The data for conventional MRI characteristics and lesion localization between RCC and CPA groups are summarized in Table 2. While all the RCCs and their corresponding pituitary stalks appeared at the same levels on the sagittal MRI view, the bulk of some CPAs did not overlap with their corresponding pituitary stalks on the sagittal view. We therefore combined types 2 and 3 , in order to compare the common localization of RCCs with those of CPAs.

The agreement between the two readers was high $(\kappa$ $=0.926$ ). The ROC curve was performed, and the following two variables exhibited good performances in diagnosing RCCs: the coronal localization (sensitivity, 91.1\%; specificity, 79.4\%; AUC = 0.853, 95\% confidence interval: 0.778
- 0.910, $\mathrm{P}<0.0001$ ), and sagittal localization (sensitivity, 88.9\%; specificity, 91.2\%; AUC $=0.889,95 \%$ confidence interval: 0.821 - 0.939, $\mathrm{P}<0.0001$ ) (Figure 3 ). There were no differences between the groups about T1 and T2 signal intensity, the presence of fluid-fluid level and an intracystic nodule ( $\mathrm{P}=0.2765,0.0624,0.0140$, and 0.8161 , respectively). The AUCs of these variants are successively 0.570 (95\% confidence interval: 0.478 - 0.658), 0.605 (95\% confidence interval: 0.513 - 0.692), 0.583 (95\% confidence interval: 0.491 - 0.671), and 0.510 (95\% confidence interval: 0.419 - 0.601). Since cyst localization provided valuable clues for the differential diagnosis between RCCs and CPAs, a suggested diagnostic pathway is outlined in Figure 4.

\section{Discussion}

To better understand the features of RCCs, we compared these 90 RCCs with 34 pituitary adenomas, the most common neoplasms found in the sella turcica. All adenomas were cystic, which might lead to a misdiagnosis of RCC by MRI. There were no significant differences between the groups in sex or age, but symptoms did differ between the two types of lesions. Space-occupying lesions causing symptoms were the most common symptom in the RCC group, but were also common in the CPA group (16/34). So differentiation cannot be made by symptoms alone.

In view of the origin, we first detailed the localization of RCCs on the coronal and sagittal views, finding these to be statistically different between the groups. To the authors' knowledge, this is the first study to use detailed localization of RCC, very easily observed, as a basis for diagnosis.

The localization of RCC correlates with the origin of pituitary gland and the Rathke's pouch. Two components of the pituitary gland, the adenohypophysis and neurohypophysis, are of different ectodermal origins. Cells in the anterior wall of Rathke's pouch proliferate rapidly, forming the pars distalis (the anterior lobe of the pituitary gland), while cells from the posterior wall differentiate into the pars intermedia, then extend superiorly to become the pars tuberalis (9-11) (Figure 5). This is the development of the adenohypophysis. During the fifth week of gestation, the pouch fuses dorsally with the infundibulum $(9,10)$, which gradually gives rise to the median eminence, the infundibular stem, and the pars nervosa of the neurohypophysis, also known as the posterior lobe of the pituitary (9). The infundibular stem, along with the pars tuberalis, comprises the pituitary stalk (10).

Traditional embryology makes clear two pertinent points. First, Rathke's cleft normally detaches from the oral epithelium (9-11). If it fails to regress and be obliterated, the cleft may dilate and be filled with fluid or mu- 
A

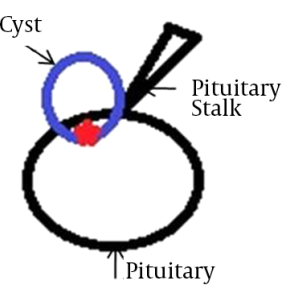

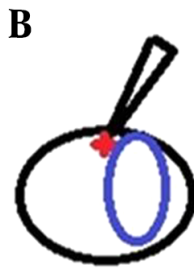

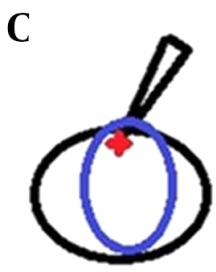

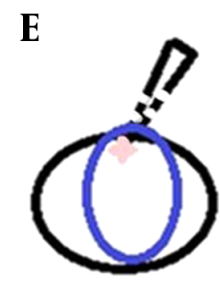

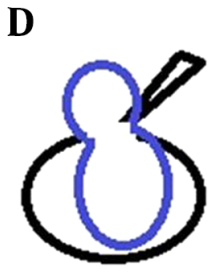

Figure 1. Types of localization of Rathke's cleft cyst (RCC) or cystic pituitary adenoma (CPA) in reference to the junction of the pituitary stalk.
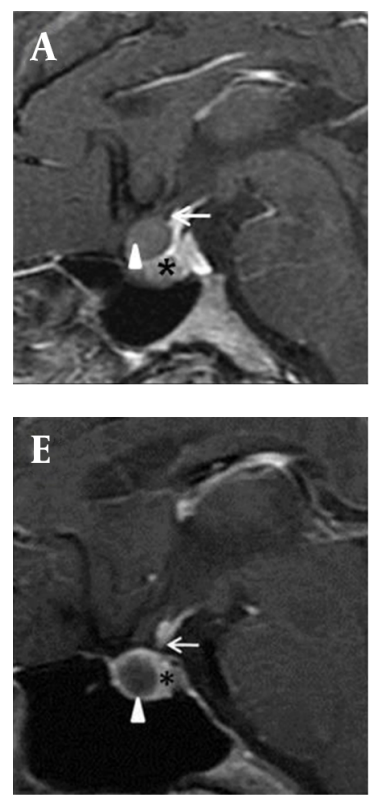
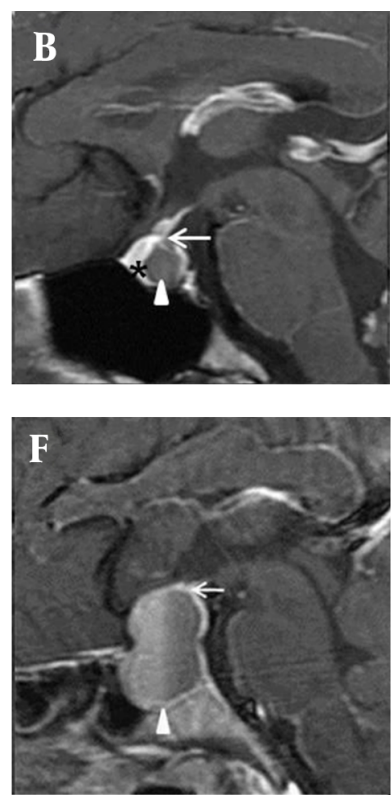
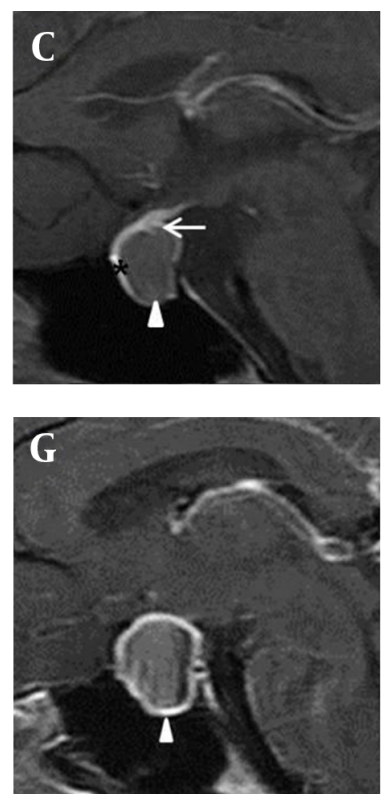
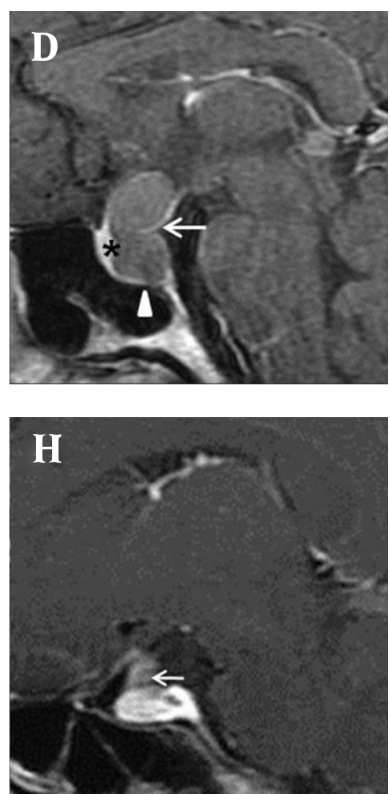

Figure 2. Localization of the lesion in reference to the junction of the pituitary stalk with the pituitary gland on sagittal, contrast-enhanced, T1-weighted images. A-D, Rathke's cleft cyst (RCC); E - H, Cystic pituitary adenoma (CPA). Triangle: lesion, arrow: junction of the pituitary stalk, asterisk: pituitary gland.

cus, resulting in a RCC. This histological and anatomic basis of RCC formation also explains why most RCCs are located between the anterior and posterior lobes of the pituitary (10-12). Some authors have suggested that the cyst could appear anywhere along the usual migration path of Rathke's pouch $(12,13)$. Second, the adenohypophysis develops closely with the neurohypophysis, especially the median parts (the pars intermedia and pars tuberalis), along with the infundibular stem. It is believed that contact between these two structures is necessary to provide neuroectodermal signaling for proliferation and later cell fate determination of pituitary cells (14). The infundibular stem, along with the pars tuberalis, comprises the pituitary stalk (11).

Our series revealed three localization types of the RCC on the sagittal view, with different connections with the pituitary stalk. We suppose that Rathke's pouch, located between the anterior and posterior lobes of the pituitary gland, might be separated into supra-anterior and infraposterior parts by the infundibulum during gestation. If the supra-anterior portion of Rathke's cleft remains and enlarges into a cyst, the inferior margin of the cyst would be located in front of the junction of the pituitary stalk with the pituitary gland (type 1). Otherwise, if the infraposterior portion enlarges, the superior margin of the cyst would lie behind the junction of the pituitary stalk when the cyst is small (type 2), but could stretch across it once the cyst is dilates to a sufficient degree (type 3 ). If both portions are retained and enlarge, the cyst might form with a snowman or figure-eight appearance. Such cysts usually extend across the pituitary stalk and encircle it (type 3). Furthermore, the midline localization of RCCs on the coronal view coordinates with the position of Rathke's pouch. The reason might be the pars tuberalis, consisting of the pituitary 
Table 2. Differences in MRI Characteristics on MRI Between Rathke's Cleft Cyst (RCC) and Cystic Pituitary Adenoma (CPA) Groups

\begin{tabular}{|c|c|c|c|c|}
\hline MRI Characteristics & RCC & CPA & P Value & AUC \\
\hline T1 signal ${ }^{\mathbf{a}}$ & & & 0.2765 & 0.570 \\
\hline Нуро- & 10 & 6 & & \\
\hline Iso & 6 & 4 & & \\
\hline Hyper- & 53 & 7 & & \\
\hline Mixed & 21 & 17 & & \\
\hline T2 signal $^{\mathrm{a}}$ & & & 0.0624 & 0.605 \\
\hline Нyро- & 28 & 8 & & \\
\hline Iso & 4 & 1 & & \\
\hline Hyper- & 31 & 7 & & \\
\hline Mixed & 27 & 18 & & \\
\hline Intracystic nodule $^{\text {b }}$ & $23(25.6)$ & $2(5.9)$ & 0.8161 & 0.510 \\
\hline Fluid-fluid level $^{\mathbf{b}}$ & $1(1.1)$ & $6(17.6)$ & 0.0140 & 0.583 \\
\hline Coronal localization (no stalk shift/stalk shift) ${ }^{b}$ & $83 / 7(92.2)$ & $7 / 27(20.6)$ & $<0.0001$ & 0.853 \\
\hline Sagittal localization (Type $2+3 /$ the rest) ${ }^{b}$ & $80 / 10(88.9)$ & $3 / 31(8.8)$ & $<0.0001$ & 0.889 \\
\hline
\end{tabular}

${ }^{a}$ MRI signals were classified as hypo-intensity, iso-intensity, hyper-intensity and mixed intensity.

balues are expressed as No. (\%).

Abbreviations: AUC,area under the curve.

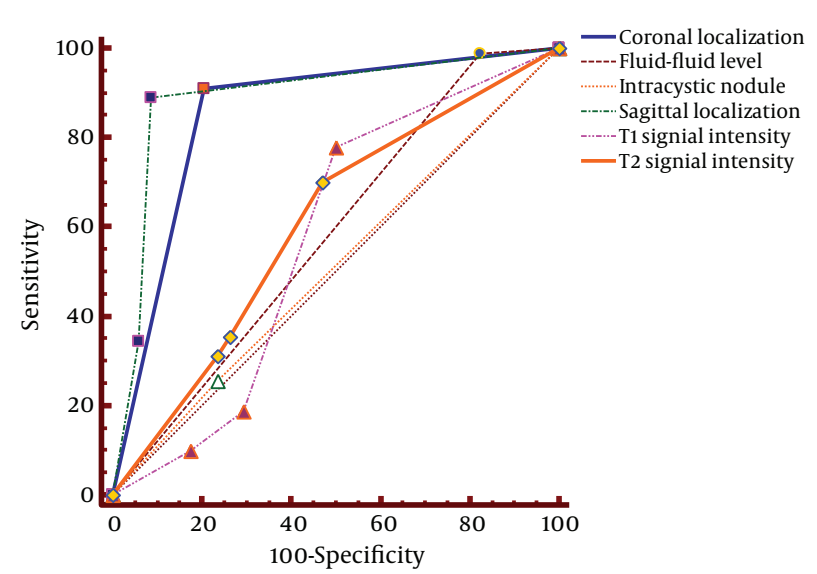

Figure 3. Graph depicts receiver operating characteristic (ROC) curves of conventional MRI characteristics and lesion localization. Localization on the sagittal and coronal views is the most effective for the differentiation between Rathke's cleft cyst (RCC) and cystic pituitary adenoma (CPA) (area under the curve $[\mathrm{AUC}]=0.889,0.853$ respectively).

stalk, also develops from the Rathke's pouch. No matter how the Rathke's cleft enlarges into a cyst (RCC), the pituitary stalk could not be shifted easily.

As mentioned above, the localization of RCCs in reference to the pituitary gland makes sense in terms of their embryological development. Conversely, a pituitary adenoma is formed by proliferation of the anterior wall of
Rathke pouch (15). Prolactinoma and growth hormonesecreting adenoma, the two most common types, are often located laterally in the sella turcica $(16,17)$. Thus, a lateral localization with shift of the pituitary stalk is considered valuable for diagnosing a pituitary adenoma, except for the adrenocorticotropic hormone-secreting adenoma, which is often located at midline, overlapping with the RCC to a certain degree $(16,17)$.

This interpretation matches the embryological theory. The diagnostic performance according to the pituitary origin is excellent. ROC analysis obtained the highest AUC = 0.889 with the sagittal localization and AUC $=0.853$ with the coronal localization respectively.

It has been suggested that RCCs can be diagnosed on MRI based on shape, signal intensity, enhancement features, and an intracystic nodule, if present (3-6). However, these characteristics are also present in other cystic sellar lesions. For example, wall enhancement reportedly provides information regarding the nature of cystic lesions, such as whether they are neoplastic or not (3-6). However, it is difficult to see the enhancement of the thin wall of an RCC through the enhancing normal pituitary gland surrounding it, especially when there is a partial volumeaveraging effect (18). That is the reason why we did not record the enhancement features of lesions in this study.

Conventional MRI characteristics also helped to distinguish the two types of lesions. In the present study, RCCs 


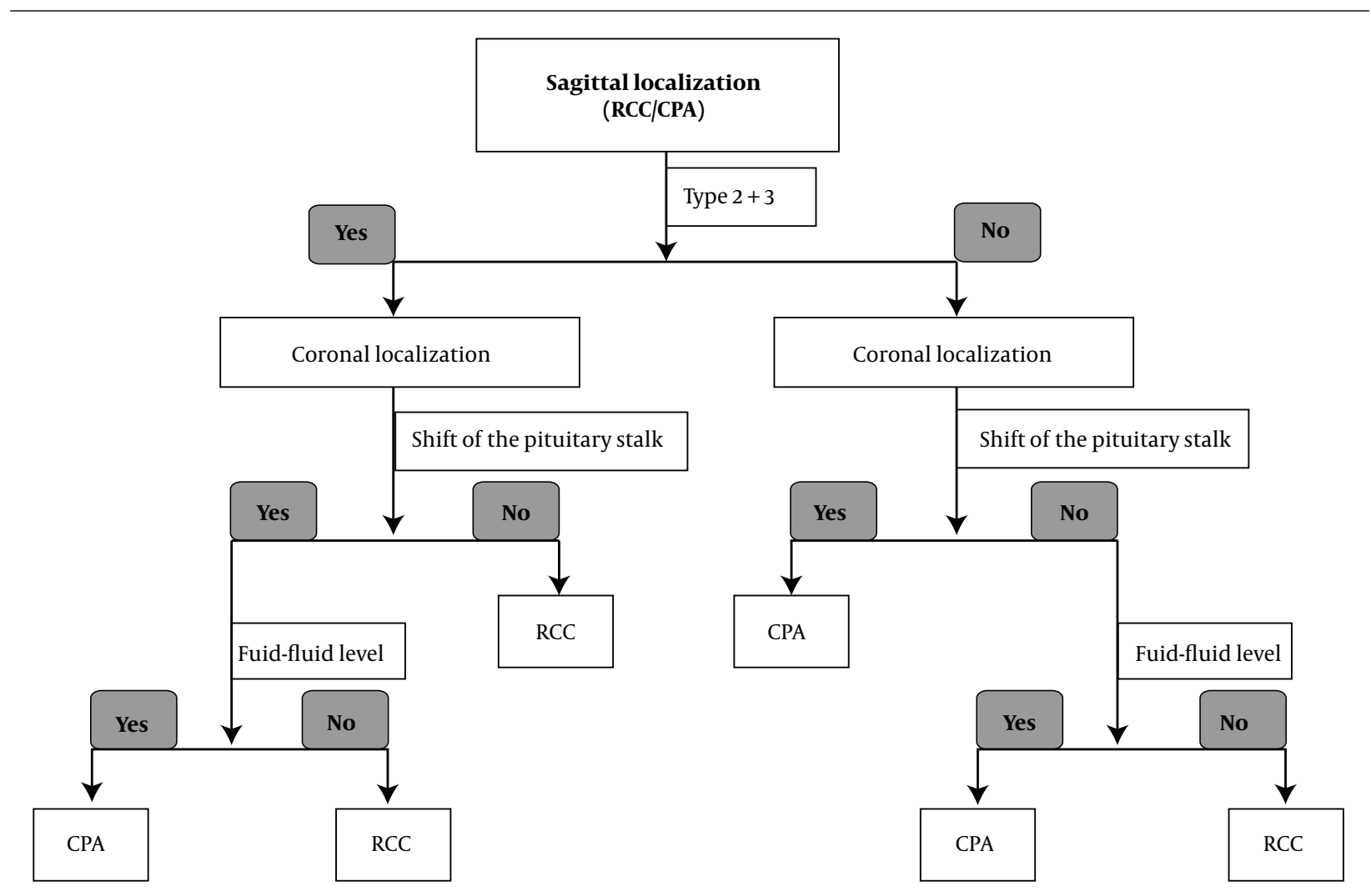

Figure 4. Flowchart for decision making in the differentiation of Rathke's cleft cyst (RCC) from cystic pituitary adenoma (CPA)
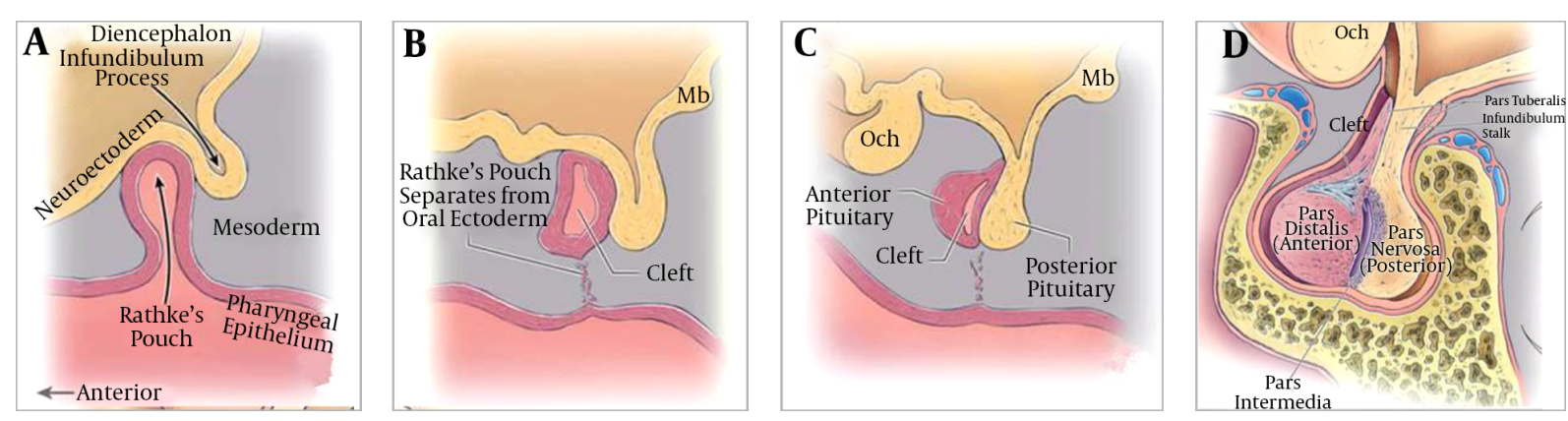

Figure 5. Development of the pituitary gland (11). A, 4th week of gestation; B, 5th week of gestation; C, D, 3rd - 5th month of gestation.

tended to display hyper-intensity on $\mathrm{T} 1$ images, and to have intracystic nodules, which is consistent with previous publications (19-22). However, these features were not effective for differential diagnosis. MRI signal intensity depends on the composition of the cyst, which may include protein, mucopolysaccharides, and cholesterol $(23,24)$. Hence intensity is insufficient for making the diagnosis. In various previous studies, intracystic nodules have been regarded to have diagnostic value for RCC. While our series found no difference between RCCs and CPAs. The nodules corre- spond to protein concretions inside the cyst, which is difficult to distinguish from acute hemorrhage observed in pituitary apoplexy. CPAs are due to cystic degenerations, it is believed to be the result of hemorrhage or necrosis (25). It must be the reason why no difference about the intracystic nodule, which also explains the presence of fluid-fluid level was relatively specific for CPAs.

There were several limitations to the present study. First, it was a retrospective study, which may have caused a selection bias. Second, there were few comparison ade- 
noma cases included, with only one type of cystic lesion. Studies with more cases, including cystic lesions of different types, such as craniopharyngiomas, need to be performed in the future to validate these preliminary results.

In conclusion, Cyst localization, observed easily on MRI, can be used as an effective parameter for diagnosing RCC and distinguishing it from a CPA. It is thought to relate to the Rathke's pouch, which might to be separated into supra-anterior and infra-posterior parts by the infundibulum during gestation.

\section{Acknowledgments}

This study was supported by chongqing scientific \& technological support funds (cstc2014jcyjA10067) and National Key clinical specialties construction program of China.

\section{References}

1. Baskin DS, Wilson CB. Transsphenoidal treatment of non-neoplastic intrasellar cysts. A report of 38 cases. J Neurosurg. 1984;60(1):8-13. doi: 10.3171/jns.1984.60.1.0008. [PubMed: 6689730].

2. Raghunath A, Sampath S, Devi BI, Chandramouli BA, Lal GJ, Chickabasaviah YT, et al. Is there a need to diagnose Rathke's cleft cyst preoperatively?. Neurol India. 2010;58(1):69-73. doi: 10.4103/00283886.60402. [PubMed: 20228467].

3. Choi SH, Kwon BJ, Na DG, Kim JH, Han MH, Chang KH. Pituitary adenoma, craniopharyngioma, and Rathke cleft cyst involving both intrasellar and suprasellar regions: differentiation using MRI. Clin Radiol. 2007;62(5):453-62. doi: 10.1016/j.crad.2006.12.001. [PubMed: 17398271].

4. Kunii N, Abe T, Kawamo M, Tanioka D, Izumiyama H, Moritani T. Rathke's cleft cysts: differentiation from other cystic lesions in the pituitary fossa by use of single-shot fast spin-echo diffusion-weighted MR imaging. Acta Neurochir (Wien). 2007;149(8):759-69. discussion 769. doi: 10.1007/s00701-007-1234-x. [PubMed: 17594050].

5. Binning MJ, Liu JK, Gannon J, Osborn AG, Couldwell WT. Hemorrhagic and nonhemorrhagic Rathke cleft cysts mimicking pituitary apoplexy. J Neurosurg. 2008;108(1):3-8. doi: 10.3171/JNS/2008/108/01/0003. [PubMed: 18173304].

6. Gaddikeri S, Vattoth S, Riley KO, DeHoff GW, Smith CB, Combs JT, et al. Rathke cleft cyst. MRI criteria for presumptive diagnosis. Neurosciences (Riyadh). 2013;18(3):258-63. [PubMed: 23887217].

7. Wald NJ, Bestwick JP. Is the area under an ROC curve a valid measure of the performance of a screening or diagnostic test?. J Med Screen. 2014;21(1):51-6. doi: 10.1177/0969141313517497. [PubMed: 24407586].

8. Lin XZ, Wu ZY, Li WX, Zhang J, Xu XQ, Chen KM, et al. Differential diagnosis of pancreatic serous oligocystic adenoma and mucinous cystic neoplasm with spectral CT imaging: initial results. Clin $\mathrm{Ra}$ diol. 2014;69(10):1004-10. doi: 10.1016/j.crad.2014.05.003. [PubMed: 24919983].
9. Zada G, Lin N, Ojerholm E, Ramkissoon S, Laws ER. Craniopharyngioma and other cystic epithelial lesions of the sellar region: a review of clinical, imaging, and histopathological relationships. Neurosurg Focus. 2010;28(4). E4. doi:10.3171/2010.2.FOCUS09318. [PubMed: 20367361].

10. Wajima D, Yonezawa T, Masui K, Aketa S. Relationship Between Clinical Features and T2-Weighted Magnetic Resonance Images in Symptomatic Rathke Cleft Cysts. World Neurosurg. 2016;88:421-7. doi: 10.1016/j.wneu.2015.10.018. [PubMed: 26485415].

11. Han SJ, Rolston JD, Jahangiri A, Aghi MK. Rathke's cleft cysts: review of natural history and surgical outcomes. J Neurooncol. 2014;117(2):197203. doi: 10.1007/s11060-013-1272-6. [PubMed: 24146189].

12. Cho KH, Chang H, Yamamoto M, Abe H, Rodriguez-Vazquez JF, Murakami G, et al. Rathke's pouch remnant and its regression process in the prenatal period. Childs Nerv Syst. 2013;29(5):761-9. doi: 10.1007/s00381-012-2015-2. [PubMed: 23314691].

13. Oyesiku NM, Post KD. Rathke cleft cysts. Neurosurg Focus. 2011;31(1):Introduction. doi:10.3171/2011.5.FOCUS11116. [PubMed: 21721870].

14. Di Iorgi N, Allegri AE, Napoli F, Bertelli E, Olivieri I, Rossi A, et al. The use of neuroimaging for assessing disorders of pituitary development. Clin Endocrinol (Oxf). 2012;76(2):161-76. doi: 10.1111/j.13652265.2011.04238.x. [PubMed: 21955099].

15. Babu R, Back AG, Komisarow JM, Owens TR, Cummings T], Britz GW. Symptomatic Rathke's cleft cyst with a co-existing pituitary tumor; Brief review of the literature. Asian J Neurosurg. 2013;8(4):183-7. doi: 10.4103/1793-5482.125662. [PubMed: 24551002].

16. Bonneville JF, Bonneville F, Cattin F. Magnetic resonance imaging of pituitary adenomas. Eur Radiol. 2005;15(3):543-8. doi:10.1007/s00330004-2531-x. [PubMed: 15627195].

17. Asa SL, Ezzat S. The pathogenesis of pituitary tumors. Annu Rev Pathol. 2009;4:97-126. doi: 10.1146/annurev.pathol.4.110807.092259. [PubMed: 19400692].

18. Byun WM, Kim OL, Kim D. MR imaging findings of Rathke's cleft cysts: significance of intracystic nodules. AJNR Am J Neuroradiol. 2000;21(3):485-8. [PubMed: 10730639].

19. Nishioka H, Haraoka J, Izawa H, Ikeda Y. Magnetic resonance imaging, clinical manifestations, and management of Rathke's cleft cyst. Clin Endocrinol (Oxf). 2006;64(2):184-8. doi: 10.1111/j.13652265.2006.02446.x. [PubMed: 16430718].

20. Wang SS, Xiao DY, Yu YH, Jing JJ, Zhao L, Wang RM. Diagnostic Significance of Intracystic Nodules on MRI in Rathke's Cleft Cyst. Int J Endocrinol. 2012;2012:958732. doi: 10.1155/2012/958732. [PubMed: 23008711].

21. Mendelson ZS, Husain Q, Elmoursi S, Svider PF, Eloy JA, Liu JK. Rathke's cleft cyst recurrence after transsphenoidal surgery: a meta-analysis of 1151 cases. J Clin Neurosci. 2014;21(3):378-85. doi: 10.1016/j.jocn.2013.07.008. [PubMed: 24269553].

22. Guo SY, Cai XQ, Ma J, Wang WY, Lu G. Diagnosis of concomitant pituitary adenoma and Rathke's cleft cyst with magnetic resonance imaging. Int J Surg. 2015;18:191-5. doi: 10.1016/j.ijsu.2015.05.001. [PubMed: 25959251].

23. Wen L, Hu LB, Feng XY, Desai G, Zou LG, Wang WX, et al. Rathke's cleft cyst: clinicopathological and MRI findings in 22 patients. Clin Radiol. 2010;65(1):47-55. doi: 10.1016/j.crad.2009.09.010. [PubMed: 20103421].

24. Zhong W, You C, Jiang S, Huang S, Chen H, Liu J, et al. Symptomatic Rathke cleft cyst. J Clin Neurosci. 2012;19(4):501-8. doi: 10.1016/j.jocn.2011.07.022. [PubMed: 22336224].

25. Goel A, Shah A, Jhawar SS, Goel NK. Fluid-fluid level in pituitary tumors: analysis of management of 106 cases. J Neurosurg. 2010;112(6):1341-6. doi:10.3171/2009.11.JNS091083. [PubMed: 19961310]. 